\title{
Higher minor hemoglobin A2 levels in multiple sclerosis patients correlate with lesser disease severity
}

\author{
Muhammed Emin Ozcan' \\ Bahri Ince ${ }^{2}$ \\ Hasan Huseyin Karadeli ${ }^{3}$ \\ Asuman Gedikbasi ${ }^{4}$ \\ Talip Asil ${ }^{3}$ \\ Meric A Altinoz ${ }^{5}$ \\ 'Department of Neurology, Biruni \\ University, ${ }^{2}$ Centre for Mood \\ Disorders, Bakirkoy Research and \\ Training Hospital for Psychiatry, \\ ${ }^{3}$ Department of Neurology, \\ Bezmialem University, ${ }^{4}$ Department \\ of Biochemistry, Sadi Konuk Bakirkoy \\ State Hospital, ${ }^{5}$ Department of \\ Immunology, Experimental Medicine \\ Research Institute (DETAE), Istanbul \\ University, Istanbul, Turkey
}

This article was published in the following Dove Press journal:

Neuropsychiatric Disease and Treatment

16 August 2016

Number of times this article has been viewed

Objective: To define whether minor adult hemoglobin A2 (HbA2, $\alpha 2 \delta 2)$ exerts any protective activity in multiple sclerosis (MS).

Methods: $\mathrm{HbA} 2$ levels were measured in $146 \mathrm{MS}$ patients with high performance liquid chromatography and association with MS Severity Scores (MSSS) were determined. HbA2 associations with blood count parameters were also studied using blood counts evaluated on the same day of high performance liquid chromatography sampling. Routine biochemical parameters were also determined to rule out elusively influential factors, such as anemia and thyroid disorders.

Results: HbA2 levels negatively correlated with MSSS (Spearman correlation, $R$ : -0.186 , $P=0.025$ ). Exclusion of confounding factors with a generalized linear model revealed an even stronger negative correlation between $\mathrm{HbA} 2$ and MSSS $(P<0.001)$. HbA2 positively correlated with red blood cells $(\mathrm{RBCs})(R=0.350, P<0.001)$ and in turn, $\mathrm{RBCs}$ negatively correlated with $\operatorname{MSSS}(R=-0.180, P=0.031)$. Average HbA2 levels were highest among patients treated with interferon $\beta 1 \mathrm{a}$.

Conclusion: $\mathrm{RBC}$ fragility is increased in $\mathrm{MS}$, and recent data suggest that circulating free $\mathrm{Hb}$ contributes to neural injury in MS. $\mathrm{HbA} 2$ and its oxidative denaturation product hemichrome $\mathrm{A} 2$ enhance RBC membrane stability to a greater extent than do major $\mathrm{HbA}$ or hemichrome A. Reductions in ischemic cerebrovascular vascular events are reported in $\beta$-thalassemia carriers and $\mathrm{HbA} 2$ levels are considerably higher in this population. Episodic declines of cerebral blood flow were shown in bipolar disorder, and we have recently shown a protective role of $\mathrm{HbA} 2$ against postpartum episodes in females with bipolar disorder. HbA2's erythroprotective functions may reduce free $\mathrm{Hb}$ and long-term neural injury in MS.

Keywords: multiple sclerosis, erythrocytes, adult minor hemoglobin, hemoglobin A2

\section{Introduction}

Multiple sclerosis (MS) is a chronic neuroinflammatory disease and the most frequent cause of neurological disability in young adults. Current treatments decrease the attacks but may fail to prevent long-term progression. Therefore, illuminating novel deteriorating and protective factors in MS is of crucial importance. Almost 50 years ago, red blood cell (RBC) fragility was found to be increased in MS and even more so during the attacks $(P<0.01)$. ${ }^{1}$ These observations were neglected until the past few years and no one questioned the influence of RBC fragility and free hemoglobin (Hb) in MS. But this has changed in recent years. ${ }^{2-6}$ In 2009, an impaired fluidity of RBC membranes in MS was reported. ${ }^{2}$ In 2011, circulating free $\mathrm{Hb}$ was shown to disrupt the blood-brain barrier, accompanied by iron deposition, lipid peroxidation, and perivascular inflammation. ${ }^{3}$ In 2014, chronic subclinical extravasation of free $\mathrm{Hb}$
Correspondence: Meric A Altinoz

Department of Immunology, Experimental Medicine Research Institute (DETAE), Istanbul University, Guven Sk. No: 5 D:6, Istanbul 34406,

Turkey

Tel +9053620l 8327

Email maltinoz@gmail.com 
was proposed as an important neurodegenerative component in MS. ${ }^{4}$ In 2015, it was found that degradation products of free $\mathrm{Hb}$ damaged myelin, where globin triggered myelin basic protein oxidative cross-linking, and heme transferred to the lipids involved in lipid peroxidation. ${ }^{5}$ Although the $\mathrm{RBC}$ count is within the normal range in MS patients, it shows an inverse correlation with the disease duration and Expanded Disability Status Scale (EDSS). ${ }^{6}$ In adults, three Hb'sexist: Major HbA ( $\alpha 2 \beta 2, \sim 96 \%-97 \%$ ), and minor Hb's HbA2 $(\alpha 2 \delta 2,<3 \%$ ), and $\mathrm{HbF}$ (F for fetal, $\alpha 2 \gamma 2,<0.6 \%){ }^{7}$ Until now, no study has questioned the role of minor adult Hbs in MS, which affects RBC stability. In this study, we investigated the associations between $\mathrm{HbA} 2$ levels and MS Severity Scores (MSSS).

\section{Materials and methods}

\section{Study design and patient selection}

A total of 146 consecutive MS patients who were admitted to the MS polyclinic at Bezmialem University Hospital between January 2014 and March 2015 were enrolled in the study after their written informed consent forms were obtained. Inclusion criteria required patients to be aged between 17 and 65 years and to have at least graduated elementary school. The study was started following the approval of the Bezmialem University Hospital Ethics Committee (approval number: 71306642/050-01-04/78; approval date: March 19, 2014). Two neurologists with clinical experience on MS confirmed the diagnosis according to the Revised McDonald's Diagnostic Criteria (2010). All the patients underwent a detailed physical examination and anamnesis. Patients suffering from any disease associated with hypoxia (lung disease, cardiac or cerebral stroke) or consuming antiretroviral drugs were excluded due to possible interference with HbA2 levels. The extent of the physical disability in MS patients was measured with the EDSS. An established MSSS was employed, which is obtained by dividing EDSS value from the disease duration in order to represent the disease severity as a whole rather than cross-sectional. ${ }^{8}$

\section{High performance liquid chromatography methodology of minor $\mathrm{Hb}$ analysis}

The blood samples were collected in Vacutainer tubes (Becton-Dickinson, Franklin Lakes, NJ, USA) containing ethylenediaminetetraacetic acid. Blood samples were kept at $4{ }^{\circ} \mathrm{C}$ at least for 1 week. They were then processed on the HLC-723 G7 (Tosoh Bioscience, Rivoli, Italy) analyzer. This analyzer is a fully automated high performance liquid chromatography system using reagents and conditions specifically designed to separate and quantify $\mathrm{HbA} 2, \mathrm{HbF}$, and the most frequent $\mathrm{Hb}$ variants.

\section{Statistical analysis}

For the statistical analysis, Number Cruncher Statistical System $^{\circledR} 2007$ (NCSS, LLC, Kaysville, UT, USA) was used. Values of average, standard deviation, median, frequency, rate, minimum, and maximum were used as descriptive statistics. For quantitative variables without normal distribution, Mann-Whitney $U$-test was employed for comparing two groups, and Kruskal-Wallis test was employed for comparing three or more groups. Spearman correlation was used to define the correlations between quantitative variables. Generalized linear model was employed to determine the combined effect of modifying factors on the MSSS. Significances were evaluated at $P<0.01$ and $P<0.05$. To analyze the different levels of $\mathrm{HbA} 2$ in different drug groups, the Kruskal-Wallis test was first employed if there was a general difference between different drug groups. Thereafter, Bonferroni correction and Mann-Whitney $U$-test were used to analyze differences between the different drug regimes.

\section{Results}

Table 1 demonstrates the demographic characteristics and treatment groups of the study population. Average age of the

Table I Demographic characteristics and treatment groups of the study population

\begin{tabular}{|c|c|}
\hline Study population & $\begin{array}{l}\mathrm{N}(\%) / \text { mean } \pm \mathrm{SD} / \\
\text { median }(\mathrm{Q} \mathbf{I}, \mathrm{Q} 3)\end{array}$ \\
\hline \multicolumn{2}{|l|}{$\operatorname{Sex}(n)$} \\
\hline Male & 45 (3।\%) \\
\hline Female & 101 (69\%) \\
\hline Age (years) & $39.21 \pm 10.9$ \\
\hline Age of disease onset (years) & $30.53 \pm 9.44$ \\
\hline Duration of illness (years) & $8.68 \pm 7.14$ \\
\hline EDSS & I.5 (I-2.625) \\
\hline MSSS & $2.93 \pm 2.65$ \\
\hline \multicolumn{2}{|l|}{ Smoking (n) } \\
\hline$(+)$ & $55(37.7 \%)$ \\
\hline$(-)$ & $91(62.3 \%)$ \\
\hline \multicolumn{2}{|l|}{ Treatment groups ( $n$ ) } \\
\hline Drug free & $12(8.2 \%)$ \\
\hline Interferon $\beta$ Ia & $60(41.1 \%)$ \\
\hline Interferon $\beta \mathrm{Ib}$ & $12(8.2 \%)$ \\
\hline Glatiramer acetate & $34(23.3 \%)$ \\
\hline Fingolimod & $23(15.8 \%)$ \\
\hline Natalizumab & I (0.7\%) \\
\hline Dimethyl fumarate & I (0.7\%) \\
\hline Azathioprine & $2(1.4 \%)$ \\
\hline Cyclophosphamide & I $(0.7 \%)$ \\
\hline
\end{tabular}

Notes: QI, first quartile; Q3, third quartile.

Abbreviations: EDSS, expanded disability status scale; MSSS, Multiple Sclerosis Severity Scores; SD, standard deviation. 
patients was of $39.21 \pm 10.90$ years; 101 cases $(69.2 \%)$ were females and 45 (30.8\%) were males. Except for five cases, which were treated either with azathioprine $(n=2)$, natalizumab $(n=1)$, dimethyl fumarate $(n=1)$, and cyclophosphamide $(n=1)$, all treatment groups included 12 or more patients. $\mathrm{HbA} 2$ levels were higher in relapsing remitting MS than progressive cases (primary progressive MS + secondary progressive MS), (2.17 [Q1: 2.07, Q3: 2.36] versus 2.11 [Q1: 1.85, Q3: 2.29]), in which the difference was close to significance $(P=0.053)$.

Table 2 demonstrates all variables that may possibly influence MSSS, including demographical and biochemical parameters, and significances that were determined via Spearman correlation. All biochemical parameters listed in Table 2 were within normal limits in the whole study population (data not shown). With Spearman analyses, it was revealed that the age and mean corpuscular volume (MCV) had significant positive

Table 2 Analyses of variables that correlate with the MSSS

\begin{tabular}{|c|c|c|}
\hline \multirow[t]{2}{*}{ Analyzed variables } & \multicolumn{2}{|l|}{ MSSS } \\
\hline & Median (QI, Q3) & $P$-value \\
\hline Sex & & $0.478^{\mathrm{a}}$ \\
\hline Female & $\mathrm{I} .77(0.7 \mathrm{I}, 4.27)$ & \\
\hline Male & $2.26(0.88,4.82)$ & \\
\hline Disease type & & $<0.00 I^{\mathrm{a}, * *}$ \\
\hline RRMS & $1.34(0.64,2.65)$ & \\
\hline SPMS + PPMS & $6.64(4.38,8.3 \mathrm{I})$ & \\
\hline Smoking (package/year) & & $0.066^{\mathrm{b}}$ \\
\hline 0 & I.77 $(0.76,4.68)$ & \\
\hline $1-9$ & $1.45(0.53,2.65)$ & \\
\hline \multirow[t]{2}{*}{$\geq 10$} & $3.34(1.04,5.94)$ & \\
\hline & $r$ & $P$-value \\
\hline$\overline{\text { Age }}$ & 0.396 & $<0.00 I^{* *}$ \\
\hline Age of disease onset (years) & -0.192 & $0.020^{*}$ \\
\hline Smoking & 0.127 & 0.126 \\
\hline RBC & -0.180 & $0.03 I^{*}$ \\
\hline $\mathrm{Hb}$ & -0.060 & $0.47 \mid$ \\
\hline $\mathrm{MCV}$ & 0.197 & $0.018^{*}$ \\
\hline $\mathrm{Fe}$ & -0.018 & 0.854 \\
\hline Ferritin & -0.037 & 0.700 \\
\hline Vitamin $\mathrm{B} / 2$ & 0.151 & 0.110 \\
\hline Folate & 0.019 & 0.843 \\
\hline Vitamin D & -0.046 & 0.640 \\
\hline TSH & -0.143 & 0.198 \\
\hline $\mathrm{HbF}$ & 0.037 & 0.711 \\
\hline $\mathrm{HbA2}$ & -0.186 & $0.025^{*}$ \\
\hline
\end{tabular}

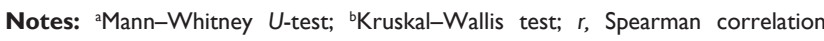
coefficient; ${ }^{*} P<0.05$; ${ }^{*} P<0.0$ I; $\mathrm{Q}$ I, first quartile; $Q 3$, third quartile. Age and MCV correlated positively; while age of disease onset, $\mathrm{RBC}$ and $\mathrm{HbA} 2$ values correlated negatively with MSSS.

Abbreviations: $\mathrm{Hb}$, hemoglobin; $\mathrm{HbA} 2$, hemoglobin $\mathrm{A} 2$; $\mathrm{MCV}$, mean corpuscular volume; MSSS, Multiple Sclerosis Severity Score; PPMS, primary progressive MS; RBC, red blood cell; RRMS, relapsing remitting MS; SPMS, secondary progressive MS; TSH, thyroid-stimulating hormone. correlations with MSSS $(R=0.396, P<0.001$ and $R=0.197$, $P=0.018$, respectively). On the other hand, age of disease onset, $\mathrm{RBC}$, and $\mathrm{HbA} 2$ had significant negative correlations with $\operatorname{MSSS}(R=-0.192, P=0.020 ; R=-0.180, P=0.031$; and $R=-0.186, P=0.025$, respectively). HbA2 levels positively correlated with $\mathrm{RBC}(R=0.292, P<0.001)$ and negatively with red cell distribution width - standard deviation (RDWsd; $R=-0.281, P=0.001)$. We did not find any association between the other blood count parameters and $\mathrm{HbA} 2$ or MSSS. There were no correlations between the MSSS and $\mathrm{Hb}$, iron, ferritin, vitamin B12, folic acid, vitamin D, thyroid-stimulating hormone, and $\mathrm{HbF}(P>0.05)$. Table 3 demonstrates the results of a generalized linear model, which we have employed for a more precise evaluation of the modifying factors on MSSS. In this model, MSSS was determined as a dependent variant; while age, age of the disease onset, RBC, MCV, HbA2, and smoking were determined as possible covariants. The evaluations revealed that the proposed model exerted a high significance $(P<0.001)$, and it was shown that age and $\mathrm{HbA} 2$ statistically significantly affected the MSSS. If the influence of the other covariants was excluded, a single unit increase in age increased MSSS 1.018-fold (odds ratio [OR; 95\% confidence interval [CI]: 1.018, (1.001-1.035)]; P: 0.019). For the $\mathrm{HbA} 2$, if the influence of the other covariants was excluded, a single unit increase of $\mathrm{HbA} 2$ decreased MSSS 0.399-fold (OR [95\% CI: 0.399, (0.247-0.644)]; $P<0.001)$ with a much higher significance.

Figure 1 is a box plot graph depicting median $\mathrm{HbA} 2$ values in different treatment groups. Groups including $<12$ patients were omitted. Kruskal-Wallis test revealed a significant difference in $\mathrm{HbA} 2$ levels between the five different treatment groups $(P=0.033)$. Bonferroni correction of the MannWhitney $U$-test results demonstrated that MS patients treated with interferon (IFN)- $\beta 1$ a had prominently higher levels of

Table 3 Results of the generalized linear model of the MSSS

\begin{tabular}{lllll}
\hline $\begin{array}{l}\text { Analyzed } \\
\text { variables }\end{array}$ & Beta & Exp (B) & $\begin{array}{l}\text { Exp (B) for } \\
\mathbf{9 5 \%} \mathbf{C l}\end{array}$ & P-value \\
\hline Smoking & - & $\mathrm{I}$ & & - \\
Smoking (I-9) & -0.177 & 0.838 & $(0.530,1.324)$ & 0.448 \\
Smoking ( $\geq 10)$ & 0.302 & 1.352 & $(0.876,2.087)$ & 0.173 \\
Age & 0.021 & 1.021 & $(I .003,1.039)$ & $\mathbf{0 . 0 1 9}$ \\
Age of disease onset & -0.010 & 0.990 & $(0.963,1.018)$ & 0.489 \\
RBC & -0.027 & 0.973 & $(0.629,1.506)$ & 0.902 \\
MCV & 0.029 & 1.030 & $(0.996,1.065)$ & 0.086 \\
HbA2 & -0.946 & 0.388 & $(0.220,0.685)$ & $\mathbf{0 . 0 0 I}$ \\
\hline
\end{tabular}

Notes: Please note that age and $\mathrm{HbA} 2$ significantly affected variables and also that the influence of $\mathrm{HbA} 2$ emerged stronger with a higher significance. Bold font indicates statistical significance.

Abbreviations: $\mathrm{HbA} 2$, hemoglobin $\mathrm{A} 2$; $\mathrm{MCV}$, mean corpuscular volume; MSSS, MS Severity Score; RBC, red blood cell; Cl, confidence interval. 


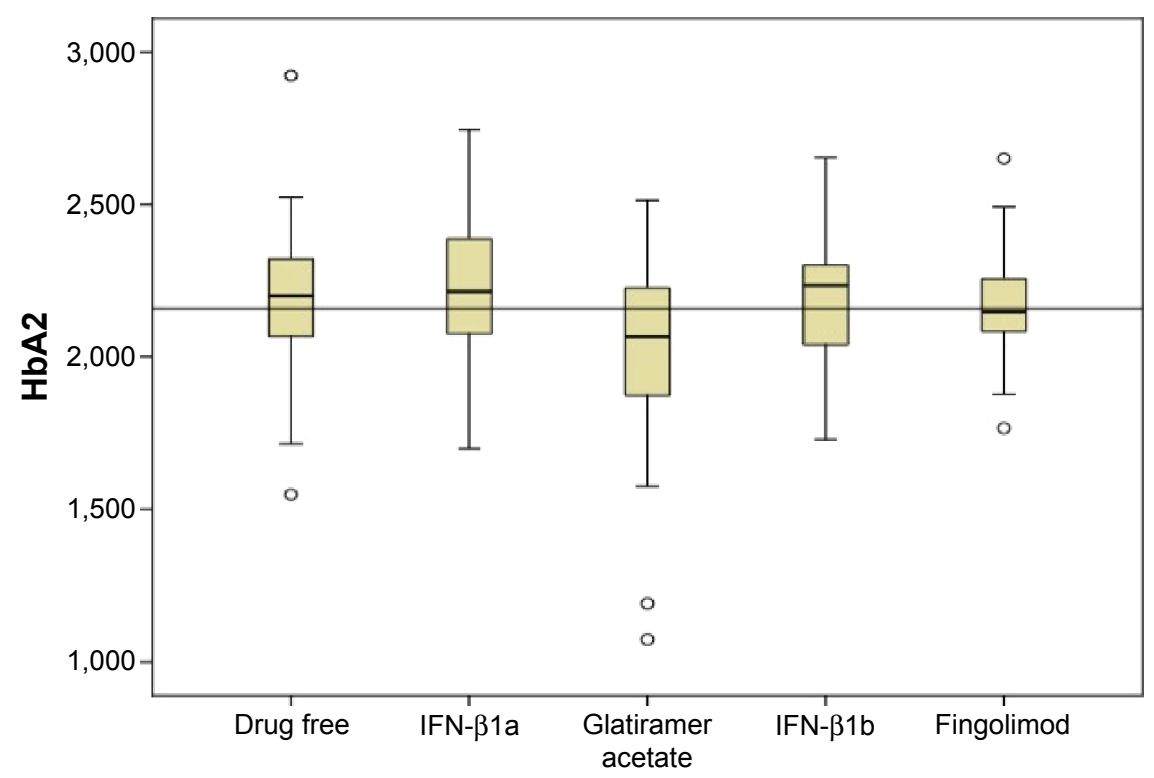

Figure I Box plot graph depicting median $\mathrm{HbA} 2$ values in different treatment groups.

Notes: A reference line was drawn to represent the median $\mathrm{HbA} 2$ level in the whole study group. Treatment groups including $<12$ patients were omitted. MS patients treated with IFN- $\beta$ I a had prominently higher levels of $\mathrm{HbA} 2$ in comparison to those treated with glatiramer acetate $(P=0.002)$.

Abbreviations: $\mathrm{HbA} 2$, hemoglobin $\mathrm{A} 2$; IFN- $\beta$ I, interferon- $\beta$ I; MS, multiple sclerosis.

$\mathrm{HbA} 2$ in comparison to those treated with glatiramer acetate $(P=0.002)$. No difference was seen between the other drug regime or the untreated group $(P>0.05)$.

\section{Discussion}

Until now, $\mathrm{HbA} 2$ was regarded mostly as nonfunctional, yet few studies have demonstrated the likely protective activity of $\mathrm{HbA} 2$ under stressful conditions. Level of $\mathrm{HbA} 2$ increases during ischemic cardiac events and decreases following recovery. ${ }^{9,10}$ Both $\mathrm{HbA} 2$ and $\mathrm{HbF}$ increase during myocardial infarcts, ${ }^{11}$ yet only the $\beta$-thalassemia trait, which induces higher $\mathrm{HbA} 2$, reduces the risk of ischemic cardiac event. ${ }^{12}$ $\mathrm{HbA} 2$ and its denaturation product hemichrome $\mathrm{A} 2$ bind to the $\mathrm{RBC}$ membrane proteins to a greater extent than do major $\mathrm{HbA}$ or hemichrome A and exert higher stability. ${ }^{13}$ Thermal stability of $\mathrm{HbA} 2$ is highest among the unstable $\mathrm{Hb}$ variants and the native major $\mathrm{HbA} .{ }^{14} \mathrm{HbA} 2$ controls the RBC shape via regulating the $\mathrm{K}-\mathrm{Cl}$ cotransport and tuning the cell $\mathrm{pH} .{ }^{15}$ Total $\mathrm{Hb}$ levels differ between males and females, and free $\mathrm{Hb}$ levels fluctuate depending on the presence of hemolytic conditions, such as infections. On the other hand, sex, race, and infections do not influence HbA2 levels. ${ }^{16,17}$ Therefore, measuring $\mathrm{HbA} 2$ levels would give reliable results pertinent to its involvement in chronic diseases, somewhat analogous to the benefits of $\mathrm{HbA} 1 \mathrm{C}$ determination in diabetes, which allows determining the glucose balance for a long period rather than cross-sectional. Although circulating free $\mathrm{Hb}$ is scavenged by plasma haptoglobin, chronic hemolysis can saturate the free $\mathrm{Hb} /$ heme scavenging system. ${ }^{18}$ Hence, a persistent protective factor against hemolysis may alter the course of any chronic disease, which is influenced by the toxic insults of free $\mathrm{Hb}$.

In this study, it was revealed that the age of disease onset negatively correlated with MSSS $(R=-0.192, P=0.020)$, while patients age positively correlated MSSS $(R=0.396$, $P<0.001)$. These findings indicate trustable data, since MS patients with earlier age of onset have a milder MS course, while a continuing disease process in the long-term deteriorates the clinical condition and increases MSSS. ${ }^{19}$ Our data, discussed later, are also congruent with previous findings, which showed inverse correlation between the RBC counts and EDSS in MS patients. ${ }^{6}$ In this current investigation, the two most statistically significant findings were that higher $\mathrm{HbA} 2$ levels correlated with higher RBC levels $(R=0.357, P<0.001)$ and prominently lesser MSSS $(P<0.001)$. These findings can be attributed to erythroprotective actions of $\mathrm{HbA} 2$, which reduces hemolysis and subsequent release of the neurotoxic free $\mathrm{Hb}$.

Several additional data obtained in this current study further strengthen this hypothesis. 1) RBC counts negatively correlated with MSSS $(R=-0.180, P=0.031)$, supporting the idea that lesser hemolysis may reduce MS disease severity. 2) MCV positively correlated with MSSS $(R=0.197$, $P=0.018)$. Higher MCV values likely reflect compensatory erythropoiesis against higher chronic hemolysis, since MCV 
within normal limits correlates with active reticulocyte production. $\left.{ }^{20,21} 3\right) \mathrm{HbA} 2$ negatively correlated with RDWsd $(R=-0.281, P=0.001)$. Similar to MCV, RDWsd within normal limits reflects the extent of active erythropoiesis and juvenile RBCs. ${ }^{22,23}$ Hence, a negative correlation between the $\mathrm{HbA} 2$ and RDWsd likely suggest a lesser stimulation of $\mathrm{RBC}$ production due to lower rates of chronic hemolysis in patients having higher levels of $\mathrm{HbA} 2$.

Since $\delta$-thalassemias are clinically silent, $\mathrm{HbA} 2$ is largely assumed as nonfunctional. However, among the primate $\delta$-globin genes, the rate of nonsynonymous substitutions is much lesser than the rate of synonymous substitutions, suggesting its unexplored importance and evolutionary conservation. ${ }^{24}$ Human locus of the $H B D$ gene encoding $\delta$-globin is inside the $\beta$-globin gene cluster at the chromosomal region $11 \mathrm{p} 15.5$. Whole genome screen for linkage in Sardinian multiplex families with MS using 327 markers revealed linkage in three regions including $11 \mathrm{p} 15.5{ }^{25}$ Another whole genome screen study in Nordic countries with high MS prevalence by typing 399 microsatellite markers in 136 sibling-pairs revealed 17 regions above the nominal significance including $11 \mathrm{p} 15.5 .{ }^{26} 11 \mathrm{p} 15.5$ is a region where important immunoregulatory genes reside and which is subject to epigenetic control. ${ }^{27}$ Hence, $H B D$ gene may also exert haplotypal interactions with immunoregulatory genes.

Another recent finding is that $\mathrm{Hb}$ chains are expressed in human brain; ${ }^{28}$ yet we do not know currently whether peripheral $\mathrm{Hb}$ levels correlate with cerebral expression. Living at high altitudes increases both $\mathrm{HbA} 2$ and $\mathrm{HbF}$ as compensatory responses against limited oxygen supply. ${ }^{29,30}$ We have recently shown that $\mathrm{HbA} 2$ and $\mathrm{HbF}$ correlated with the episode density in bipolar disorder, where intermittent cerebral hypoxia is considered among the etiologies. ${ }^{31}$ Furthermore, the sum of $\mathrm{HbA} 2$ and $\mathrm{HbF}$ correlated with the episode density more significantly. ${ }^{31}$ Yet only $\mathrm{HbA} 2$, but not $\mathrm{HbF}$, exerted protection against postpartum episodes in bipolar disorder-suffering females with completed pregnancy. ${ }^{31}$ Similarly, analysis of $\mathrm{HbF}$ levels in this current study revealed no correlation between $\mathrm{HbF}$ and MSSS. This is an evidence that RBC stabilization underlies the protective activity of $\mathrm{HbA} 2$ in $\mathrm{MS}$, although $\mathrm{HbA} 2$ also binds oxygen with an affinity higher than major $\mathrm{Hb} .{ }^{10}$

In adults, compensatory increases of $\mathrm{HbF}$ occur in globin chain disorders, such as sickle cell anemia and $\beta$-thalassemia major. ${ }^{32}$ Thus, pharmacological HbF induction emerged as a strategy to treat some such patients who missed the chance of marrow transplantation due to hemosiderosis. ${ }^{32}$
Different drugs, including hydroxyurea and valproic acid, were discovered as inducers of $\mathrm{HbF}$, which alleviates the severity of $\beta$-thalassemia major. ${ }^{32}$ But very recent studies have shown that inducing $\mathrm{HbA} 2$ may be more efficient. ${ }^{33}$ In adults, $\mathrm{HbF}$ is expressed only in a small fraction of blood cells $(<2 \%)$, whereas $\mathrm{HbA} 2$ is always expressed pancellularly, although at lower rates..$^{33}$ Indeed, genetic induction of $\mathrm{HbA} 2$ exerted dramatic therapeutic effects in thalassemic mice. ${ }^{33}$ On the other hand, we have very limited knowledge of drugs capable of inducing $\mathrm{HbA} 2$. Hence, higher $\mathrm{HbA} 2$ levels in IFN- $\beta 1$ a-treated patients deserve attention. While common infections and cancers do not influence $\mathrm{HbA} 2,{ }^{17}$ its levels increase in psoriasis and rheumatic fever. ${ }^{34,35}$ Hence, it is likely that differing cytokine micromilieu may differentially influence $\mathrm{HbA} 2$ synthesis. Since $\mathrm{HbA} 2$ exerts a higher thermal stability, ${ }^{14}$ cytokines associated with specific febrile responses may induce $\mathrm{HbA} 2$ synthesis. It was also shown that reverse transcriptase inhibitor zidovudine, but not tenofovir, elevates $\mathrm{HbA} 2$ and zidovudine-containing antiretroviral treatment regimes improve neurocognitive functioning in AIDS patients more efficiently. ${ }^{36,37}$ Whether this efficacy is related to the differential reduction of viral load or to additional neuroprotective effects of $\mathrm{HbA} 2$ remains to be investigated. A possible statistical drift may have occurred (in the generalized linear model) due to differing drug regimes in the study population. Nonetheless, such a limitation is unavoidable, since the indications of these different drugs are determined - by international guidelines according to the differing disease features. Hence, even if the drugs were taken into account and added to the generalized linear model, unavoidable changes would still occur due to different pathobiological endophenotypes of MS When we pooled the data of IFN- $\beta-1 \mathrm{a}$ and IFN- $\beta-1 \mathrm{~b}$, the obtained significances did not change (data not shown), yet we preferred to present these groups separately, since these two drugs cannot be considered to act through completely same mechanisms.

$\beta$-Thalassemia carriers have reduced risk of ischemic cerebrovascular accidents, which may be explained with lower cholesterol, hematocrit, blood viscosity, and blood pressure due to chronic hemolysis. ${ }^{38}$ Remembering the fact that $\mathrm{HbA} 2$ levels increase over $3 \%$ in this population, well above the average levels in our study population, a protection against ischemic cerebrovascular accidents may also involve the protective functions of $\mathrm{HbA} 2$.

\section{Disclosure}

The authors report no conflicts of interest in this work. 


\section{References}

1. Caspary EA, Sewell F, Field EJ. Red blood cell fragility in multiple sclerosis. Br Med J. 1967;2(5552):610-611.

2. Hon GM, Hassan MS, van Rensburg SJ, et al. Red blood cell membrane fluidity in the etiology of multiple sclerosis. J Membr Biol. 2009; 232(1-3):25-34.

3. Butt OI, Buehler PW, D'Agnillo F. Blood-brain barrier disruption and oxidative stress in guinea pig after systemic exposure to modified cellfree hemoglobin. Am J Pathol. 2011;178(3):1316-1328.

4. Bamm VV, Harauz G. Hemoglobin as a source of iron overload in multiple sclerosis: does multiple sclerosis share risk factors with vascular disorders? Cell Mol Life Sci. 2014;71(10):1789-1798.

5. Bamm VV, Lanthier DK, Stephenson EL, Smith GS, Harauz G. In vitro study of the direct effect of extracellular hemoglobin on myelin components. Biochim Biophys Acta. 2015;1852(1):92-103.

6. Hon GM, Hassan MS, van Rensburg SJ, Erasmus RT, Matsha T. The haematological profile of patients with multiple sclerosis. Open J Mod Neurosurg. 2012;2(3):36-44.

7. Figueiredo MS. The importance of hemoglobin A2 determination. Rev Bras Hematol Hemoter. 2015;37(5):287-289.

8. Roxburgh RH, Seaman SR, Masterman T, et al. Multiple Sclerosis Severity Score: using disability and disease duration to rate disease severity. Neurology. 2005;64(7):1144-1145.

9. Damianova L, Popnikolov S, Pencheva B, Angelova A. Changes in the hemoglobin A2 level of patients with ischemic heart disease. Vutr Boles. 1989;28(2):28-31.

10. Damyanova L. Electrophoretic HbA2 assessment in ischemic heart disease. Z Med Lab Diagn. 1989;30(8):437-439.

11. Zarubina EG. Structural alterations in erythrocyte membranes in patients with myocardial infarction. Voen Med Zh. 2002;323(2):34-36.

12. Bozdar M, Ahmed S, Anwar J. Relative protection from ischaemic heart disease in beta-thalassaemia carriers. J Coll Physicians Surg Pakistan. 2010;20(10):653-656.

13. Ranney HM, Lam R, Rosenberg G. Some properties of hemoglobin A2. Am J Hematol. 1993;42:107-111.

14. Chakrabarti A, Bhattacharya D, Deb S, Chakraborty M. Differential thermal stability and oxidative vulnerability of the hemoglobin variants, $\mathrm{HbA} 2$ and HbE. PLoS One. 2013;8(11):e81820.

15. Wong P. A hypothesis on the role of the electrical charge of haemoglobin in regulating the erythrocyte shape. Med Hypotheses. 2004;62(1): 124-129.

16. Denic S, Agarwal MM, Al Dabbagh B, et al. Hemoglobin A2 lowered by iron deficiency and $\alpha$-thalassemia: should screening recommendation for $\beta$-thalassemia change? ISRN Hematol. 2013; 2013:858294.

17. Alperin JB, Dow PA, Petteway MB. Hemoglobin A2 levels in health and various hematologic disorders. Am J Clin Pathol. 1977;67(3): 219-226.

18. Hanson MS, Xu H, Flewelen TC, et al. A novel hemoglobin-binding peptide reduces cell-free hemoglobin in murine hemolytic anemia. Am J Physiol Heart Circ Physiol. 2013;304(2):H328-H336.

19. Zaffaroni M, Ghezzi A. The prognostic value of age, gender, pregnancy and endocrine factors in multiple sclerosis. Neurol Sci. 2000; 21(4 Suppl 2):S857-S860.

20. Bessman D. Erythropoiesis during recovery from iron deficiency: normocytes and macrocytes. Blood. 1977;50(6):987-993.
21. Bolan CD, Conry-Cantilena C, Mason G, Rouault TA, Leitman SF. MCV as a guide to phlebotomy therapy for hemochromatosis. Transfusion. 2001;41(6):819-827.

22. Roberts GT, El Badawi SB. Red blood cell distribution width index in some hematologic diseases. Am J Clin Pathol. 1985;83(2):222-226.

23. Pierce $\mathrm{CN}$, Larson DF. Inflammatory cytokine inhibition of erythropoiesis in patients implanted with a mechanical circulatory assist device. Perfusion. 2005;20(2):83-90.

24. Spritz RA, Giebel LB. The structure and evolution of the spider monkey delta-globin gene. Mol Biol Evol. 1988;5(1):21-29.

25. Coraddu F, Sawcer S, D'Alfonso S, et al. A genome screen for multiple sclerosis in Sardinian multiplex families. Eur J Hum Genet. 2001;9(8): 621-626.

26. Akesson E, Oturai A, Berg J, et al. A genome-wide screen for linkage in Nordic sib-pairs with multiple sclerosis. Genes Immun. 2002;3(5): 279-285.

27. Altinoz MA, Gedikoglu G, Deniz G. $\beta$-Thalassemia trait association with autoimmune diseases: $\beta$-globin locus proximity to the immunity genes or role of hemorphins? Immunopharmacol Immunotoxicol. 2012;34(2): 181-190.

28. Biagioli M, Pinto M, Cesselli D, et al. Unexpected expression of alphaand beta-globin in mesencephalic dopaminergic neurons and glial cells. Proc Natl Acad Sci U S A. 2009;106(36):15454-15459.

29. Son Yu A. Quantitative estimation of hemoglobin and its fractions in permanent mountain dwellers in the Tyan'-Shan' and Pamir. Hum Physiol. 1979;5(2):208-210.

30. Risso A, Fabbro D, Damante G, Antonutto G. Expression of fetal hemoglobin in adult humans exposed to high altitude hypoxia. Blood Cells Mol Dis. 2012;48(3):147-153.

31. İnce B, Guloksuz S, Altınbaş K, Oral ET, Alpkan LR, Altinoz MA. Minor hemoglobins $\mathrm{HbA} 2$ and $\mathrm{HbF}$ associate with disease severity in bipolar disorder with a likely protective role of $\mathrm{HbA} 2$ against postpartum episodes. J Affect Disord. 2013;151(1):405-408.

32. Altinoz MA, Ozdilli K, Carin MN, Gedikoglu G. Medroxyprogesteronevalproic acid - aspirin. MVA regime to reduce transfusion associated mortality in late-term hemoglobinopathies. Hypothesis and rationale. Med Hypotheses. 2007;68(6):1342-1347.

33. Manchinu MF, Marongiu MF, Poddie D, et al. In vivo activation of the human $\delta$-globin gene: the therapeutic potential in $\beta$-thalassemic mice. Haematologica. 2014;99(1):76-84.

34. Zlatkov N, Damianova L, Prodanov K, Kiriakova N. Hemoglobin A2 and F in patients with psoriasis. Dermatol Monatsschr. 1990;176(7):403-406.

35. Reddi YR, Sudhakar Rao V, Reddi GD, Niranjan Rao P, Nair R, Ahuja YR. Elevated hemoglobin-A2 levels in rheumatic fever and rheumatic heart disease: a new finding. Indian Pediatr. 1976;13(2):153-154.

36. Bhagat P, Kaur Sachdeva R, Sharma P, et al. Effect of antiretroviral therapy on hemoglobin A2 values can have implications in antenatal beta-thalassemia screening programs. Infect Dis (Lond). 2016; 48(2):122-126.

37. Winston A, Puls R, Kerr SJ, et al. Dynamics of cognitive change in HIV-infected individuals commencing three different initial antiretroviral regimens: a randomized, controlled study. HIV Med. 2012;13(4): 245-251.

38. Karimi M, Borhani Haghighi A, Raisi H, Giti R, Namazee MR. Is betathalassemia trait a protective factor against ischemic cerebrovascular accidents? J Stroke Cerebrovasc Dis. 2008;17(2):79-81.
Neuropsychiatric Disease and Treatment

\section{Publish your work in this journal}

Neuropsychiatric Disease and Treatment is an international, peerreviewed journal of clinical therapeutics and pharmacology focusing on concise rapid reporting of clinical or pre-clinical studies on a range of neuropsychiatric and neurological disorders. This journal is indexed on PubMed Central, the 'PsycINFO' database and CAS,

\section{Dovepress}

and is the official journal of The International Neuropsychiatric Association (INA). The manuscript management system is completely online and includes a very quick and fair peer-review system, which is all easy to use. Visit http://www.dovepress.com/testimonials.php to read real quotes from published authors. 